\title{
Motivated to Express: Salience of Oppression Toward Other Women Encourages Women's Self-Expression
}

\author{
Maya Al-Khouja ${ }^{1}$, Netta Weinstein ${ }^{2}$, Nicole Legate ${ }^{3}$ \\ [1] Department of Psychology, Cardiff University, Cardiff, United Kingdom. [2] Department of Psychology, University of Reading, Reading, United Kingdom. \\ [3] Department of Psychology, Illinois Institute of Technology, Chicago, IL, USA.
}

Journal of Social and Political Psychology, 2021, Vol. 9(1), 290-305, https://doi.org/10.5964/jspp.6757

Received: 2020-06-15 • Accepted: 2021-04-19 • Published (VoR): 2021-07-22

Handling Editor: Johanna Ray Vollhardt, Clark University, Worcester, MA, USA

Corresponding Author: Maya Al-Khouja, Department of Psychology, Cardiff University, 70 Park Place, Cardiff, United Kingdom. E-mail: Alkhoujama@cardiff.ac.uk

\begin{abstract}
Women's oppression undermines and inhibits women but may also prompt an enterprising reaction. In this paper, three studies explored the extent to which women respond to awareness of the oppression of other women with an increased desire for selfexpression, a reactive but constructive response. Study 1 explored reactions to two forms of other women's oppression: restricted selfexpression and restricted economic opportunities. Women reported an increased desire to self-express after exposure to either form of oppression, as compared to a control group. Study 2 compared British women's reactions to stories of a woman versus a man being oppressed, finding the former group wrote more words about an unrelated, but timely and consequential topic (Brexit). Finally, Study 3 replicated the effect of greater self-expression after being exposed to women's oppression, and furthermore identified an indirect effect through reactance. Findings are discussed in relation to identity, constructive forms of reactance, and implications for current women's rights movements.
\end{abstract}

\section{Keywords}

sexism, oppression, reactance, gender, self-expression

Women experience restricted freedoms more often than men. These restrictions can take numerous forms, for example less economic independence and reduced self-expression (Nussbaum \& Glover, 1995), constraints that affect women's health and well-being (Moss, 2002). Typically, research relating to these restrictions within society have focused on the inhibiting impact that sexism, the unequal treatment of women within society, has on women. For example, sexism negatively affects women's cognitive performance (Dardenne, Dumont, \& Bollier, 2007), self-perceptions of their bodies (Shepherd et al., 2011), and well-being (Barreto, Ellemers, Cihangir, \& Stroebe, 2009). Yet some data, including qualitative reports (McMahill, 2001), and a larger body of anecdotal evidence (Sakr, 2004), suggests that women can respond to sexism by expressing themselves more; in other words, women faced with sexism may be especially motivated to self-express. This paper explores this possibility: that when observing the sexist oppression of other women, women may be motivated to express themselves more, perhaps because the restricted freedoms elicit a desire to defy oppressive norms.

\section{Women's Oppression}

Sexism can be understood as a form of oppression, defined as the unequal power relations between individuals, genders, classes, communities, and nations (Lorber, 1994). This disproportionate distribution of power leads to conditions of 
inequality, exploitation, marginalization and social injustices (Apfelbaum, 1999). For women, a large consequence of these inequalities includes barred access to the same economic opportunities that men have (e.g., Card, Cardoso, \& Kline, 2015). These economic inequalities jeopardize women's well-being, with implications for lowered life expectancy and greater risk of mental health outcomes such as depression (e.g., Belle \& Doucet, 2003).

The extant body of work has primarily focused on how women accept, or internalize, unfair or oppressive social norms. In contexts where oppression is normative, women are more likely to censure themselves (Jack \& Dill, 1992). Such internalization is exacerbated by social contexts in which women anticipate negative consequences for self-expression (Swim, Eyssell, Murdoch, \& Ferguson, 2010). Much like social inequalities themselves, such censorship and self-censorship has implications for well-being, and has been linked to higher rates of depression (Bell \& Adams, 2016; Jack \& Dill, 1992; Thompson, 1995). Conversely, while some internalize oppression, leading to negative outcomes such as depression (Jack \& Dill, 1992), it may be that other women react to oppression by externalizing or fighting it, as shown in other forms of oppression and stigma (Corrigan \& Watson, 2002). Research has also shown the ability to freely express oneself may be a healthier response to oppression than internalizing the stigma (Itzchakov, DeMarree, Kluger, \& Turjeman-Levi, 2018).

\section{Reasserting Self-Expression}

Though empirical work has focused on the ways in which women internalize social norms and inequalities, cases of women actively seeking self-expression in restricted or oppressive settings are increasing. For example, self-expression can take private forms including dress and the expression of one's opinions in private, safe places (Mack, 1995; Miller, 1997). More recently, with the development of new technologies, women in westernized societies also express themselves publicly by expressing their personal identity on social media, with studies suggesting women express themselves more than men in this way (e.g., Dhir, Pallesen, Torsheim, \& Andreassen, 2016; Manago, Graham, Greenfield, \& Salimkhan, 2008). In more restricted societies, women seek ways to express themselves even given limited opportunities to do so, for example by structuring independent leisure activities (e.g., recreation), including their own time and space, to offer opportunities for self-expression (Freysinger \& Flannery, 1992; Shaw, 2001).

While people benefit from expressing themselves, some of these efforts for women may be directly related to their felt oppression; for example, the possibility for oppression to foster expression can help explain how movements such as "Me Too" gain traction, which has inspired women to speak out about injustice (Hosterman, Johnson, Stouffer, \& Herring, 2018). However, intriguingly, women may similarly express themselves in domains unrelated to the oppression because they more broadly feel the need to respond to the dissatisfactory feeling of having been oppressed. These instances may provide a safer venue for compensating for otherwise restrictive conditions. For example, women may express themselves more in safe contexts (e.g., with friends, on social media, and in women-only groups; Lewis, Sharp, Remnant, \& Redpath, 2015) when experiencing or witnessing in-group oppression, but this has yet to be examined. Furthermore, we know that merely the knowledge of oppression of other women may inspire a desire to fight oppression, as theorists have described women embracing their own self-expression as a rebellious or passionate desire to defy oppressive cultural norms (Bartlett, 2004; Hooks, 2000). Although the motive to self-express is documented in societies with relatively restrictive norms, in societies which are lower in the overt oppression of women, women's reactions to oppression might be more evident as they experience less direct threat following these reactions (e.g., Inglehart, Norris, \& Welzel, 2002).

\section{Theoretical Underpinnings of the Motive to Self-Express}

For women, and other oppressed groups, self-expression might be a mechanism to maintain a sense of self and agency. Agency in this context is defined as one's sense of individualization and self-affirmation; when people feel restricted, they may increase their efforts to exert power and influence within their surroundings (Bosworth, 2017). Previous research has found that even when women are in overtly oppressive situations, such as in an abusive relationship, they still actively take steps to preserve their sense of self and agency, such as through seeking out social support (Hage, 2006). Although self-expression has not been directly measured as an outcome of agency, expression of one's thoughts 
and feelings re-affirm their identity and sense of self (e.g., Kraus, Chen, \& Keltner, 2011), and this might be especially important in situations where oppression is overt.

The observations that women express themselves in restrictive contexts is further supported by theorizing through the motivational lens of self-determination theory. Self-determination theory posits that individuals have a need for autonomy, defined as the need to feel self-congruent and self-volitional: to experience oneself as having meaningful choices and opportunities, and the ability to express oneself honestly (Ryan \& Deci, 2017). Thus, like agency, autonomy is concerned with actions that represent oneself as a driver of action. Taken together, both theoretical approaches point to the importance of self-driven action for individuals: While agency is understood as the feelings of being a separate individual, autonomy is concerned with self-motivated actions.

Previous research has found that when autonomy need satisfaction is thwarted, individuals seek to regain homeostasis of the thwarted need and are thus even more motivated to seek out opportunities that might provide the satisfaction of the need for autonomy (Ryan \& Deci, 2017). These observations are also explained by reactance theory, which, like self-determination theory, states that when there is a threat to or loss of a freedom (e.g., through oppression) individuals are motivated to restore that freedom (e.g., by exercising their self-expression more; Brehm \& Brehm, 2013). Reactance in this case is seen as an adaptive response: feeling helpless or a loss of control leads to negative well-being outcomes and being able to react externally helps alleviate this (Wortman \& Brehm, 1975).

Evidence informed by both self-determination theory and reactance theory has suggested that in the face of controlling, oppressive forces, individuals feel a certain tense rebelliousness that drives desires to reassert freedoms. Behaviorally, the focus has been on identifying manifestations of this in terms of antisocial, unhelpful, or counterproductive actions (e.g., Fogarty, 1997; Van Petegem, Soenens, Vansteenkiste, \& Beyers, 2015).

Importantly, previous research shows such reactance can occur even if the freedom under threat is not directly related to the person. The restriction of a meaningful other's freedom can elicit reactance from an individual, just as the individual would react to personal restrictions to their freedom (Moore \& Fitzsimons, 2007). Thus, individuals do not need to experience oppression themselves, but rather must observe it in a way that is meaningful and personally connected to them. An important recent set of studies documenting this observation showed that when the autonomy of an individual's group is undermined (i.e., collective autonomy), individuals within that group feel a lowered sense of well-being, as if their own autonomy was undermined (Kachanoff, Taylor, Caouette, Khullar, \& Wohl, 2019). In other words, one's own sense of autonomy can be indirectly undermined merely through a shared group identity. According to social identity theory, this effect may be due to perceiving similarity between members who share an in-group identity (Tajfel, Turner, Austin, \& Worchel, 1979). With this in mind, we anticipated reactance on behalf of oppressed others is more likely to occur for those within the same ingroup-in this case women perceiving other women to have their freedoms restricted.

\section{Current Study and Hypothesis}

The current studies expanded the previous research in four consequential ways. First, although most empirical research has focused on women's tendency to internalize oppression to their own detriment, observations that women choose to self-express in response to oppressive contexts have not received careful empirical attention. It currently seems no studies have examined self-expression in its own right, rather than as a means of solving the particular problem initially responsible for oppressing the self-expression (e.g., expression as a driving force of prosocial behavior; Grant \& Gino, 2010). By focusing on self-expression more generally and not directly related to the source of the oppression, we begin to disentangle energy or liking for a particular cause (e.g., Me Too) versus the act of self-expressing. This is important because it is impossible to estimate the full potential for positive downstream consequences following individuals' exposure to others' self-oppression without isolating the generalizability of these reactions. Furthermore, self-expression, in and of itself, shows robust links with health (Pennebaker \& Chung, 2011).

Second, whereas findings from self-determination theory and reactance theory have focused on the external defiance of reactance, there is reason to believe that motives to reassert freedoms in the form of greater self-expression may be a more subtle form of reactance. Third, although most extant research has focused on direct oppression to the individual, recent work suggests that individuals can be affected by indirect oppression through their social group 
identity (e.g., Kachanoff et al., 2019). Finally, few experimental studies have examined issues related to self-expression. It is important to build a causal model of how individuals respond to oppression within their social groups, and experimental manipulations are key to disentangling these dynamics. We therefore conducted three experiments to test our overarching hypothesis that women exposed to the oppression of another woman (as opposed to the oppression of individuals from other groups) will show greater self-expression in response. In the third experiment we also test whether this effect can be explained by feelings of reactance, or a desire to do the opposite of demands or expectations.

\section{Study 1}

The goal of Study 1 was to test the extent to which facing women's oppression would increase desire to self-express. We examined two types of oppression women experience, namely, through reduced economic opportunity and through freedom to self-express. The two experimental conditions were contrasted against an outgroup control. Using both an economic and a self-expression oppression condition, we aimed to describe whether the desire to self-express is evident for both types of oppression. We wondered whether, alternatively, there would only be an effect when self-expression is oppressed-arguably a more proximal predictor of our outcome (desire to express).

\section{Method}

\section{Sample and Procedure}

One-hundred and fifty-two participants took part in an in-person lab study. We aimed to achieve 1- $\beta$ err probability of 0.95 for two-tailed correlations (a conservative test, given the directional hypothesis proposed) to identify an effect size of 0.3 at $90 \%$ confidence. Power calculations indicated that minimum $N=144$ was required, which was met by our sample size. Participants were female psychology university students in their first and second year of study at Cardiff University in the United Kingdom (U.K.), aged 18-24 years. Participants were randomly assigned to read one of three articles and were told the experiment looked at how people remember facts about articles they read, ensuring they read the assigned article carefully. Based on condition, experimental stimuli were designed to portray sexism in one of two ways: women oppressed through restricted self-expression or through restricted economic opportunity, and a third comparison condition portrayed oppression of journalists. Stimuli were created by combining actual articles surrounding events taking place in Egypt (Committee to Protect Journalists, 2016; Soueif, 2011). The article for the self-expression oppression condition described the oppression of women in Egypt $(n=50)$, including the story of a woman who got arrested for peacefully protesting for women's rights. The economic oppression article described oppression of women in Egypt through the lack of economic opportunities $(n=50)$. The reporter oppression article (outgroup control) described similar self-expression oppression in Egypt by the government, but towards reporters instead of women $(n=52)$. All articles were identical in terms of presentation, and similar in both word count and emotive language. After reading the randomly assigned text, participants responded to questions regarding the person portrayed. All 152 participants completed the study and were included in the final sample. Scale responses were checked for outliers at $\pm S D=2$ and no outliers were found.

\section{Measures}

Manipulation Check - After reading one of the articles, participants responded to five questions about the content of the articles and a 10-item emotion scale adapted from the Differential Emotion scale (Izard, Dougherty, Bloxom, \& Kotsch, 1974) to rate how much they felt a list of ten words accurately described the person in the article, on a 5-point scale from "Not at all" to "Completely." Five of these words referenced emotions (e.g., "sad," "angry"), and the other five, those of interest in the present study, reflected the subjective experience of losing autonomy. Four of these autonomy-thwarting words were used for our manipulation check: "trapped," "controlled," "suppressed," and "undermined" ( $\alpha=.81$ ). These terms were adapted from theoretical approaches describing the subjective experience of thwarted autonomy (Ryan \& Deci, 2017). "Subservient" was removed because it reduced reliability of the overall scale. Values were reversed scored, meaning lower values reflect lower autonomy and higher scores signify higher autonomy. 
Self-Expression Desire - Participants completed the eight-item Willingness to Self-Censor scale (Hayes, Glynn, \& Shanahan, 2005) before and after the manipulation $(\alpha$ at both times $=.85)$. This scale measures the extent of desire to self-express and was adapted for assessing experiences "in this moment." Example items include: "If someone was wrong right now, I wouldn't let them know," and "I would express my opinion around others who would disagree with me," assessed on a 5-point scale from "Strongly Disagree" to "Strongly Agree." Most items (6/8) were reverse scored so that higher scores on the scale reflected a greater desire to self-express.

\section{Results}

\section{Manipulation Check}

A manipulation check was used to find whether the two sexism articles were effective at lowering perceived autonomy. An analysis of variance (ANOVA) identified a significant main effect of the three conditions on perceived autonomy, $F(2,151)=16.46, p<.001, \eta_{\mathrm{p}}^{2}=.18$. Specifically, participants in the self-expression oppression condition reported the protagonist as having the lowest autonomy $(M=1.56, S D=0.73)$, with the reporter's oppression condition having the next lowest $(M=1.78, S D=0.84)$ and economic oppression condition as having the most autonomy $(M=2.42, S D=$ 0.75). A least significant difference (LSD) post hoc test found self-expression oppression to have significantly lower autonomy than the economic oppression condition, $t=-5.52, p<.001, d=-0.90$, but no difference was found between self-expression oppression and reporter oppression conditions, $t=-1.42, p=.16, d=-0.23$; both women and reporters were perceived as having low autonomy. Economic oppression was perceived to have significantly more autonomy than the reporter oppression condition, $t=4.16, p<.001, d=0.68$.

\section{Self-Expression Desire}

Self-expression was measured pre- and post-manipulation, and as such a standardized residual of the variance at Time 2, controlling for the variance in Time 1, was used to predict post-self-expression from condition. Results showed an increase in the desire to self-express from pre- to post-manipulation based on condition, $F(2,151)=3.35, p=.04$, $\eta_{\mathrm{p}}^{2}=.04$. A post-hoc LSD test revealed that participants in the self-expression oppression condition had a significantly higher desire to self-express, compared to the reporter's oppression condition, $t=2.39, p=.02, d=0.39$. Likewise, those in the economic oppression condition also showed a significantly increased desire to self-express compared to the reporter's oppression condition, $t=2.07, p=.04, d=0.34$. No difference was found between self-expression oppression and economic oppression conditions, $t=0.46, p=.64, d=0.07$. Main effects for Study 1 and subsequent studies are summarized in Table 1.

Table 1

Summary of All Main Effects Compared to Controls, Studies 1-3

\begin{tabular}{|c|c|c|c|c|}
\hline \multirow[b]{2}{*}{ Condition } & \multirow[b]{2}{*}{$t$} & \multirow[b]{2}{*}{$\eta_{\mathrm{p}}^{2}$} & \multicolumn{2}{|c|}{$95 \% \mathrm{CI}$} \\
\hline & & & $L L$ & $U L$ \\
\hline \multicolumn{5}{|l|}{ Self-Expression } \\
\hline \multicolumn{5}{|l|}{ Study 1} \\
\hline Expression oppression & $2.39^{*}$ & .054 & 0.08 & 0.87 \\
\hline Econ oppression & $2.07^{*}$ & .041 & 0.02 & 0.74 \\
\hline \multicolumn{5}{|l|}{ Study 2} \\
\hline Women's censorship & $2.34^{*}$ & .045 & 0.02 & 0.26 \\
\hline Men's censorship & 0.33 & .001 & -0.12 & 0.16 \\
\hline \multicolumn{5}{|l|}{ Study 3} \\
\hline Women's censorship & $4.39^{* *}$ & .106 & 1.61 & 1.92 \\
\hline \multicolumn{5}{|l|}{ Reactance } \\
\hline \multicolumn{5}{|l|}{ Study 3} \\
\hline Women's censorship & $2.81^{* *}$ & .052 & 0.08 & 0.43 \\
\hline
\end{tabular}




\section{Discussion}

Study 1 explored two types of women's oppression: restriction of self-expression and restriction of economic opportunities. Two women's oppression conditions were compared to an outgroup control condition (reporter oppression) to test the expectation that both would elicit in women a greater desire to self-express. Our findings supported this hypothesis: We found increased desire to self-express when participants were exposed to conditions that illustrated both women's self-expression oppression and women's economic oppression, as compared to the control condition. Although we tested two types of oppression: economic and self-expression, this study showed increased self-expression regardless of the type of oppression experienced, so long as it is related to the individual's ingroup. Furthermore, although the reporter oppression condition was used as an outgroup control, this may not be considered a true outgroup to our sample. Self-expression was also measured using a self-report scale of desire to self-express. In Study 2 we sought to replicate this effect using a true outgroup control condition and a behavioral indicator of self-expression.

\section{Study 2}

To conceptually replicate and expand on Study 1 findings that relied on self-report, Study 2 instead measured a behavioral indicator for self-expression: words written on a timely and consequential, but unrelated topic, namely Brexit. By focusing on an unrelated topic, but one which is important to many of our participants, we were able to isolate the desire to self-express from direct investment in the topic (e.g., gender inequality). Using this behavioral indicator of self-expression, we tested whether perceiving another women's oppression causes women to not only have an increased desire for self-expression but also act in a manner in which they express themselves more. Additionally, Study 2 employed an oppression manipulation that was arguably cleaner (viewing images), in that it reduced the chance that the specific written content within our first set of stimuli drove the effect identified in the previous study. Further, in the second study we compared women's censorship with men's censorship and included a third condition wherein women were not censored. This allowed us to understand whether effects were driven by censorship (of any individual) more generally, versus ingroup censorship driven also by women's systematic oppression (e.g., Nussbaum \& Glover, 1995).

\section{Method}

\section{Pilot Study}

Before running Study 2, a pilot study was run to test whether our behavioral indicator of self-expression, word count, was indeed reflective of self-expression. One-hundred twenty women living in the U.K. and aged 20-30 years $(M=$ 25.71, $S D=3.10$ ) were recruited through Prolific Academic to participate. Participants were asked to openly write about their "views, thoughts, or feelings on Brexit and its outcomes" and were told to write "as few or as many words as you like" using a provided textbox. Number of words written was tested as a behavioral indicator of the degree of self-expression $(M=58.61, S D=46.42)$. Participants were then given the self-expression desire scale used in Study 1 , adapted to reflect Brexit-specific self-expression (e.g., "if someone was wrong about Brexit right now, I wouldn't let them know"). As in Study 1, this scale was responded to on a 5-point scale from "Strongly Disagree" to "Strongly Agree" with most items (6 out of 8 ) reverse-scored so that higher scores on the scale reflected a greater desire to self-express. Lastly, participants answered the question "How much do you feel you expressed yourself when you wrote about Brexit previously?" on a 5-point scale from "Not very strongly" to "Very strongly." The number of words written was first checked for a normal distribution and was found to be non-normally distributed with skewness of $1.37(S E=0.22)$ and kurtosis of 1.88. The number of words written about Brexit was therefore log transformed to control for outliers before being analyzed. Results indicated that word count linked to the self-expression desire scale $(r=.20, p=.029)$ and to the perceived self-expression item $(r=.34, p<.001)$. These results indicated that the number of words written about Brexit, an unrelated topic which distinguishes self-expression from investment in the specific issue related to the oppression, might be used as a proxy for self-reported self-expression. 


\section{Sample and Procedure}

One-hundred seventy-seven female first- and second-year psychology undergraduates at Cardiff University aged 18-24 years took part in the study. To sign up for this study, participants could not have participated in the previous study. We aimed to achieve $1-\beta$ err prob of 0.95 for two-tailed correlations to identify an effect size of 0.3 at $90 \%$ confidence. Power calculations indicated that a minimum $N=144$ was required. Participants were recruited who had lived in the U.K. for a minimum of 10 years, to increase the likelihood of them having stronger views about "Brexit," the decision of whether the U.K. should leave or stay in the European Union (the topic for the written expression dependent variable). Data on race/ethnicity and immigration status was not collected. Participants were told this study evaluated how people understand others' emotions given incomplete information about facial expressions, and as such they would be viewing images of faces that are partially covered. Experimental materials were taken and adapted from a UN Women campaign "The Autocomplete Truth" (UN Women, 2013), which depicted women with neutral expressions, and mouths covered by a Google "autocomplete" search bar. This bar contained autocomplete text that expressed attitudes oppressive of women's freedoms in terms of both self-expression and economic opportunities, such as "women shouldn't vote," "women shouldn't drive," or "women should stay at home." Two such images of women were used in the women's experimental censorship condition $(n=58)$. The women's neutral condition consisted of the same two images but with blank search bars (control; $n=60$ ). In a third men's censorship condition, similar portrait photographs of men were edited so that their mouths were covered by the same google autocomplete box, which had been altered to refer to men rather than women (e.g., "men should stay at home"; $n=59$ ).

\section{Measures}

After viewing one of the three conditions, participants were given the same 10-item emotion scale used in Study 1, four of which were autonomy-thwarting items used to verify that participants saw the conditions as differentially oppressive $(\alpha=.82)$. Participants rated the photos in terms of how much they fit four autonomy-thwarting related words. As in Study 1, participants' data were collected in an in-person lab setting where full attention to the study was given, and all 177 participants who completed the study were included in the final sample. Scale responses were checked for outliers at $\pm S D=2$ and no outliers were found.

Self-Expression Behavior - Participants answered questions on the unrelated but consequential topic of Brexit. They were first told to reflect and openly write about their "views, thoughts, or feelings on Brexit and its outcomes." Participants were told to write "as few or as many words as you like." Number of words written was used as our indicator for self-expression behavior $(M=42.46, S D=32.19)$. After this, participants were also asked how strongly they feel about the Brexit vote (from 1 "Not very strongly" to 5 "Very strongly") and what position they have for Brexit ("Leave," "Remain," or "Undecided"). To control for individual differences, as people are invested in Brexit to different degrees, strength of position was selected a priori as a control variable. Word count was non-normally distributed with skewness of $1.98(S E=0.18)$ and kurtosis of 6.18. The number of words written about Brexit was therefore log and compared between the three conditions.

\section{Results}

\section{Manipulation Check}

A manipulation check was used to find whether the photos successfully made women's oppression salient. An ANOVA showed a significant main effect of condition across the three groups, $F(2,176)=26.15, p<.001, \eta_{\mathrm{p}}^{2}=.23$. Participants rated the women's censorship condition as having the lowest autonomy $(M=2.43, S D=1.02)$, and the women's neutral condition as reflecting the most perceived autonomy $(M=3.61, S D=0.83)$. The men's censorship condition was rated in between the two other conditions $(M=2.99, S D=0.81)$. A post-hoc LSD test showed a significant difference between women's censorship and women's neutral conditions, $t=-7.23, p<.001, d=-1.09$, as well as between women's censorship and men's censorship conditions, $t=-3.42, p<.001, d=-0.52$. Further, a significant difference was found between the women's neutral condition and men's censorship condition, $t=3.81, p<.001, d=0.57$. 


\section{Self-Expression Behavior}

A main effect was tested for condition, accounting for the strength of feelings toward Brexit given that individuals likely self-express more when feeling strongly about the position under discussion (Eaton \& Visser, 2008). An analysis of covariance (ANCOVA) revealed that condition had a significant main effect on the log-transformed number of words written when controlling for strength of feelings toward Brexit, $F(2,176)=5.43, p=.005, \eta_{\mathrm{p}}^{2}=.09$. This effect is still significant, but weaker when not controlling for strength of feelings toward Brexit, $F(2,176)=3.68, p=.027, \eta_{\mathrm{p}}^{2}=.04$; most likely due to the high variability in how invested people are in the topic, which contributes substantial error to the model. Therefore, we continued to control for the strength of feelings toward Brexit throughout these analyses.

Those in the women's censorship condition wrote the most words (log-transformed) $(M=1.61, S D=0.29)$ as compared to those in the women's neutral and men's censorship conditions $(M=1.46, S D=0.37 ; M=1.44, S D=0.41$, respectively). An LSD post-hoc test revealed this difference between the women's censorship condition and the other two conditions to be significant (women's neutral; $t=2.34, p=.02, d=0.35$ men's censorship; $t=2.54, p=.01, d=0.38$ ). No difference was found between women's neutral and men's censorship conditions, $t=0.33, p=.74, d=0.05$.

\section{Discussion}

By measuring the number of words participants wrote about Brexit, a topic on which many people within the U.K. have a strong opinion that could be expressed (Clarke, Goodwin, \& Whiteley, 2017), the results of Study 2 further support that reminders of women's oppression, in this case images of women being censored with oppressive messages, yields greater self-expression behaviors. Analyses controlled for the strength of attitude toward Brexit, that is, the variability in how invested participants were in the topic. However, the sample of psychology students overwhelmingly held the position of "remain"; they were generally leftwing and presumably, liberal on social policies (e.g., Ford \& Goodwin, 2017).

While Study 1 used reporters' oppression as an outgroup condition, this study used the clear outgroup condition of men's oppression. By adding a condition which depicts images of men with oppressive messages, we were able to tease apart the construct of gender from censoring: images of women being censored yielded the most self-expression, compared to images of men being censored and a neutral control condition. Additionally, no significant difference was found between the men's censorship condition and women's neutral condition. Among two female samples, we expected witnessing ingroup oppression to yield the greatest self-expression. Study 1 used self-report measures, while Study 2 used a behavioral indicator of self-expression, and both studies consistently found that women responded to another woman's oppression with a greater desire to self-express. Although these studies largely found support for the hypothesized effect, they did not explore why this reaction may have occurred. Based on self-determination theory (Ryan \& Deci, 2017) and reactance theory (Brehm \& Brehm, 2013), we anticipated that this effect might be driven by feelings of reactance that inspired a desire to reassert freedoms.

\section{Study 3}

In a final study we sought to explain the effect of greater self-expression after women's oppression was made salient in Studies 1 and 2 by testing feelings of reactance. To this end, the final study utilized the same methods as in Study 2 to replicate the effect of oppression salience on self-expression, and it expanded on the previous two studies with an additional test of reactance, which we expected would indirectly link salience of other women's oppression to one's own self-expression. While Studies 1 and 2 had limited generalizability because findings were based on student samples that were presumably relatively homogeneous in their ages and socioeconomic backgrounds, this study addresses this issue by employing a community sample. 


\section{Method}

\section{Sample and Procedure}

One-hundred fifty-one female participants aged $18-73$ years $(M=34.19$ years, $S D=10.39)$ were recruited to participate through Prolific Academic. As in previous studies, we aimed to achieve 1- $\beta$ err probability of 0.95 for two-tailed correlations to identify an effect size of 0.3 at $90 \%$ confidence and accepted additional completions of the survey. Participants were required to have voted "remain" for Brexit to ensure they were from the U.K. and keep consistency across Brexit-related views, since psychology students generally identified as remain in Study 2 (83.6\%). Two of the picture manipulations used in Study 2 were also used in this study: women's censorship $(N=80)$ and women's neutral $(N=71)$. We decided to only use one oppression condition and a neutral condition to maximize statistical power.

\section{Measures}

After viewing one of the two conditions, participants completed the 10-item emotion scale (four autonomy-thwarting items; $\alpha=.93$ ), a three-item reactance scale (see below), and the same outcome measures relating to Brexit as in Study 2. As before, strength of position was selected a priori as a control variable. The number of words written about Brexit $(M=46.89, S D=42.11)$ was non-normally distributed with skewness of $2.39(S E=0.19)$ and kurtosis of 9.92, and as such the number of words written was log transformed for analyses as in Study 2. To probe for evidence of lack of attention, scale items were checked for repetition of the same value throughout, and open-ended Brexit responses were skimmed for unrelated content. All 151 participants were found to have followed instructions and were included in the data analysis. All scale responses were checked for outliers at $\pm S D=2$ and no outliers were found.

Reactance - Three items measured general reactance felt in this moment, adapted from the Hong Psychological Reactance Scale's factors of "emotional response toward restricted choice" and "resisting influence from others" to test for state responses (Hong \& Faedda, 1996; $\alpha=.72$ ): "I want to be independent," "I would be frustrated if I could not make my own decisions" and "I would resist the attempts by others trying to influence me." Participants responded on a 5-point scale from "Strongly disagree" to "Strongly agree," $M=4.4, S D=0.55$.

\section{Results}

\section{Manipulation Check}

The same four autonomy-thwarting words (from Studies 1 and 2) were used to check that participants perceived oppression in the manipulation. An analysis of variance (ANOVA) revealed a main effect, such that participants rated the women's censorship condition $(M=2.71, S D=1.19)$ as reflecting more perceived loss of autonomy than the neutral condition $(M=3.80, S D=1.04)$, a statistically significant difference, $F(1,150)=35.53, p<.001, \eta_{\mathrm{p}}^{2}=.19$.

\section{Self-Expression Behavior}

Replicating the findings from Study 2, an ANCOVA identified a significant main effect of condition on log-transformed word count when controlling for strength of feelings toward Brexit, such that participants in the women's censorship condition $(M=1.53, S D=0.40)$ wrote significantly more words than in the neutral condition $(M=1.50, S D=0.39), F(1$, $150)=8.79, p=.004, \eta_{\mathrm{p}}^{2}=.11$. Unlike in Study 2, without controlling for strength of feelings toward Brexit, this effect was no longer significant, $F(1,150)=0.23, p=.633, \eta_{\mathrm{p}}^{2}=.00$. As in Study 2, strength of feelings toward Brexit are controlled for the remaining analyses.

\section{Reactance}

The women's censorship condition showed more reactance $F(1,150)=6.84, p=.001, \eta_{\mathrm{p}}^{2}=.09$, than the women's neutral condition. Further, greater feelings of reactance were related to a higher word count $(r=.17, p=.032)$. An indirect effect analysis was conducted using PROCESS (Hayes, 2017) to explore whether condition would be linked to self-expression behavior (i.e., words written) through reactance, given the observed effect of condition on reactance (reported above). 
The analysis obtained bias-corrected bootstrapped estimates with $95 \%$ confidence intervals and using 5,000 iterations. In line with our hypothesis, results showed that reactance explained the effect of condition predicting number of words written, that was reported above $b=-0.03, S E=0.02,95 \% \mathrm{CI}[-0.08,-0.004]$. The total effect for the mediation model was not significant $b=-0.02, S E=0.06,95 \%$ CI $[-0.15,0.11]$ (see Table 2 for analysis of statistical power for all mediation paths, computed using MedPower; Kenny, 2017).

Table 2

Study 3 Mediation Analysis Paths and Statistical Power

\begin{tabular}{lcc}
\hline Path & $\boldsymbol{B}$ & Power \\
\hline $\mathrm{a}$ & $-0.25^{*}$ & .88 \\
$\mathrm{~b}$ & $0.13^{*}$ & .34 \\
$\mathrm{c}$ (total) & -0.05 & .10 \\
$\mathrm{c}^{\prime}$ (direct) & -0.02 & .06 \\
$\mathrm{ab}$ (indirect) & $-0.03^{*}$ & .30 \\
\hline${ }^{*} p<.05$. & &
\end{tabular}

\section{Discussion}

This final study identified a mechanism that we anticipated would explain the effects found in Studies 1 and 2: Feelings of reactance partially explained why women wrote more after women's oppression was made salient. Findings directly and conceptually replicated previous ones with a direct effect of condition found on self-expression behavior (words written about Brexit): Women's oppression being made salient led to greater self-expression. Further, observing another woman's oppression increased feelings of reactance, which in turn related to greater self-expression in the form of longer written statements about one's views on Brexit.

\section{General Discussion}

In three studies we investigated the hypothesis that women would have a greater desire to self-express when faced with other women's oppression. Self-reported desire for self-expression was considered in Study 1, while behavioral self-expression-writing about one's views on the unrelated topic of Brexit, a method used to separate self-expression from investment in the topic itself-was measured in Studies 2 and 3. The focus on Brexit was strategic in our U.K. sample, selected as a topic that can be discussed at some length and one on which most hold a strong opinion that could be expressed (Vasilopoulou \& Talving, 2019). Thus, rather than assessing direct desire to respond to the needs of other women facing oppression, we were able to evaluate the extent to which the general desire to express oneself was activated through making oppression salient.

All three studies showed greater self-expression when women were exposed to other women's oppression, as compared to control conditions, regardless of whether the manipulation was in the form of a news article (Study 1) or a picture ad campaign (Studies 2 and 3). Study 3 revealed that this effect was mediated by reactance, or a desire to defy restrictions; in this case such reactance led to a constructive end, namely the desire to self-express.

These findings complement writings in feminist literature on sexism, which characterize women's desire to correct wrong doings by defying oppressive cultural norms and passionately self-expressing (Bartlett, 2004; Hooks, 2000). These findings are also consistent with previous research showing reactance can occur if a close other's freedom is under threat (Moore \& Fitzsimons, 2007), and likewise if the ingroup's collective autonomy is undermined (Kachanoff et al., 2019). These results may also help explain how recent social movements, such as the "Me Too" movement, inspire women to speak out about their own experiences and speak against injustice women face. When women read stories of other women being oppressed or silenced, among other factors (e.g., changing social norms; perceived safety; changes in 
self-esteem; Schmitt, Branscombe, \& Postmes, 2003), these stories may have produced feelings of reactance, motivating a desire for self-expression through sharing personal stories.

Although Studies 2 and 3 tested oppression as a combination of economic (through opportunities for socioeconomic advances) and self-expression (through opportunities for speech) oppression simultaneously, findings from Study 1, which separately examined both forms of oppression, showed increased self-expression when perceiving economic oppression of women alone. This is important because economic oppression of women is an occurrence worldwide, even within countries otherwise seen as modern or progressive (Burn, 2005; Gilman, 2018). Economic oppression in this sense can be observed in multiple ways: whether comparing wages of women versus men within the same line of work (Alksnis, Desmarais, \& Curtis, 2008), the disadvantages and repercussions of motherhood in certain fields (Amuedo-Dorantes \& Kimmel, 2005), or women being shut out of fields which are traditionally male-dominated and higher paying (Beede et al., 2011).

We do not consider these effects of increased self-expression as an "upside" to or a benefit of the oppression of women. Rather, increased self-expression in this case seems to be functioning as a positive coping mechanism. When people find that they, or their ingroup, are being oppressed, a negative emotional state may ensue (stress resulting from oppression) that the individual seeks to alleviate (Phillips, Adams, \& Salter, 2015). These different coping mechanisms can involve changing one's emotions regarding the oppression, facing the oppression head-on, or coping through engaging in community support. We can further categorize coping as either internalizing the oppression (such as through one's emotional states) or externalizing it through changing behaviors (such as with collective action; Corrigan \& Watson, 2002). Our results are consistent with an externalized coping reaction in that women are expressing themselves to a greater extent than they do when they are not reminded of women being oppressed. Similarly, it may be that participants in our studies experienced greater negative mood resulting from the manipulations which increased self-expression to alleviate these negative emotions. However, to understand whether this is indeed a coping response, future research would need to test for changes in mood and physiological reactivity after self-expressing in response to oppression being made salient.

The effect of increased self-expression observed throughout our studies also can be thought of as resistance to oppression. Resistance, or external coping by acting in ways which undermine power, has been thought to help offset the negative consequences of ingroup disadvantage (Leach \& Livingstone, 2015). Furthermore, resistance may not always take the form of marches or other forms of protest which could lead to punishment; indeed, resistance can undermine power on an individual, more covert level. For example, one might quit a job which has policies one does not agree with or may otherwise disrupt the hierarchy that takes advantage of marginalized groups (Rosales \& Langhout, 2020). Sociological and anthropological research has explored this type of "everyday" resistance (e.g., Johansson \& Vinthagen, 2016; Scott, 1989), but it is rarely studied in psychology, perhaps in part because of the complexities involved with observing such forms of often covert resistance (Rosales \& Langhout, 2020).

The positive psychological effects of self-expression have been documented in previous studies. For example, one intervention gave people the opportunity to express their emotions about how they are managing their breast cancer and evidenced consequent positive psychological and physical outcomes (e.g., less distress and fewer symptoms; Stanton et al., 2002). Likewise, there are negative effects on cognitive functioning and well-being when people are forced to suppress their emotional expression (e.g., Kalokerinos, Geenaway, \& Denson, 2015; Richards \& Gross, 2000). The effect of an increased desire to self-express might therefore be important for increasing positive psychological outcomes when oppression of women is made salient, and future studies should examine changes in women's mental and physical health outcomes when they are able to express themselves freely versus when they respond with more internalizing types of reactions to sexism.

The conditions manipulating oppression of self-expression across the three studies showed women being urged to self-silence (Jack \& Dill, 1992), which is worsened in contexts where negative consequences follow for speaking one's voice (Swim et al., 2010). Our findings that women desired to self-express when these tensions were made salient might reflect felt threat to the well-being of our participants faced with other women's oppression. This effect of self-expression may be sensitive to variations in individual differences, and we did not test moderators in the present studies. However, future research could examine potential moderators for the effects identified, including context-dependent factors and personality attributes. For example, social media provides women with increased opportunities for 
self-expression than they would have in everyday interactions (Manago et al., 2008) and women may be more likely to self-express through social media versus in face-to-face interactions. Personality type, such as Big-5 traits, may also play a role in the extent to which women respond with self-expression (Zillig, Hemenover, \& Dienstbier, 2002). Furthermore, feminism could be considered in this context, as we might anticipate an enhanced effect when feminist identity is strong (Burn, Aboud, \& Moyles, 2000).

The finding in Study 1 that women's self-expression and economic oppression conditions both increased the desire to self-express is noteworthy. While the reporter's self-expression oppression condition had lowered perceived autonomy, the desire for participants to self-express did not increase. This is presumably because the observed effect of increased self-expression only occurs when the in-group is involved (i.e., because both these conditions involved women specifically). This finding was replicated in Study 2, where we found outgroup oppression (men's censorship) did not promote increased self-expression. Further, the reactance effect identified in Study 3 was specific to having an ingroup's oppression (in this case, other women) made salient. Such a finding was anticipated because previous studies suggest that when a social group's collective autonomy is undermined, individuals who identify with that group are directly affected, with lowered personal autonomy and well-being (Kachanoff et al., 2019). According to this literature on collective autonomy, our observed effect may be due to a vicarious decrease in the participant's own autonomy, which should be measured future studies.

Similar effects may be evident in other disadvantaged or marginalized groups, for example, we may observe increased desire for self-expression in racial minority and sexual and gender minority groups who are reflecting on oppression of someone in their ingroup, due to reduced collective autonomy (e.g., Kachanoff, Kteily, Khullar, Park, \& Taylor, 2020). In these cases, discrimination may take the form of hostility, or restrictions on self-expression and economic oppression as was studied here (Carter \& Forsyth, 2010; Woodford, Han, Craig, Lim, \& Matney, 2014), and it is worthwhile considering whether both types of experiences elicit different outcomes and desires for self-expression.

\section{Limitations}

Several limitations of these studies bear mention. Firstly, these findings reflect a broadly Western perspective on self-expression. Self-expression has been shown to carry greater significance among people from Western cultures, to establish and affirm who they are, whereas this form of self-expression may play a lesser role in East Asian cultures (Kim \& Sherman, 2007). European Americans also benefit more from talking about their thoughts and feelings when compared with Asian Americans (Kim, Sherman, Ko, \& Taylor, 2006). Our findings should be understood in light of these cultural differences, and future studies on this topic should be conducted in non-Western countries as cognitive and motivational processes have consistently been found to differ across populations (Henrich, Heine, \& Norenzayan, 2010). In addition, our sample was fairly limited in terms of the women's background. While demographic information was limited in Study 3, as education level and socioeconomic status was not recorded, participants in Studies 1 and 2 were White, young adult students from the U.K. Results of Study 3 (where the age of participants varied from 18 to 73 years old) still replicated Study 2, which may speak to the generalizability of this effect. However, detailed information on ethnicity or other background characteristics was not recorded in these studies. We anticipate that confounds as a function of these differences were minimized through random assignment to condition. Yet, condition effects themselves may have been affected, and findings may be stronger or weaker when tested with other populations. For example, those with Middle Eastern backgrounds may identify with the vignettes used in Study 1 more than participants from the general U.K. population, as these vignettes pertained to Egypt specifically. It could also be that immigrants to the UK, particularly those from Europe, would have stronger opinions on Brexit for Studies 2 and 3, but this was not recorded to be analyzed.

The United Kingdom is a country known to be relatively gender-equal and developed. Although gender equality is expected in the United Kingdom, discrimination against women persists, for example through stereotypes and social norms (e.g., Ellemers, 2018). Further, the United Kingdom has fewer women in positions of power as compared to men, with only seven female FTSE 100 CEOs, $34 \%$ of politicians being female, and $21.7 \%$ of all police inspectors being women (Clark, 2019). There are other countries which have more serious gender-equality issues, such as more normalized gender-based violence and lack of education available to women (UN Women, 2015). From our studies we still do not 
know the specific conditions under which women self-express when seeing injustice to other women. It is critical that future research examine perceived injustice in other societies to understand whether the effects identified here generalize.

Though the present studies should be extended for a better understanding of women's desire to self-express under oppressive conditions around the globe, across three studies we found a consistent effect of increased self-expression in women when exposed to the oppression of other women. The final study revealed reactance as a mediator driving this increase. These studies reveal a likely benefit of psychological reactance, contrary to some studies which find negative effects of reactance (e.g., Legate, Weinstein, \& Przybylski, 2019). This constructive side to reactance can be seen as a force that drives individual action against oppression, which may help to explain movements like "Me Too," and other forms of women's empowerment across the globe. Since responses to oppression-outside of protests-have been rarely examined from a psychological lens, this study is a starting point to examining the breadth of responses to oppression.

Funding: The authors have no funding to report.

Acknowledgments: The authors have no support to report.

Competing Interests: The authors have declared that no competing interests exist.

\section{References}

Alksnis, C., Desmarais, S., \& Curtis, J. (2008). Workforce segregation and the gender wage gap: Is "women's" work valued as highly as

"men's"? Journal of Applied Social Psychology, 38(6), 1416-1441. https://doi.org/10.1111/j.1559-1816.2008.00354.x

Amuedo-Dorantes, C., \& Kimmel, J. (2005). The motherhood wage gap for women in the United States: The importance of college and fertility delay. Review of Economics of the Household, 3(1), 17-48. https://doi.org/10.1007/s11150-004-0978-9

Apfelbaum, E. (1999). Relations of domination and movements for liberation: An analysis of power between groups (Abridged).

Feminism \& Psychology, 9(3), 267-272. https://doi.org/10.1177/0959353599009003003

Barreto, M., Ellemers, N., Cihangir, S., \& Stroebe, K. (2009). The self-fulfilling effects of contemporary sexism: How it affects women's well-being and behavior. In M. Barreto, M. K. Ryan, \& M. T. Schmitt (Eds.), The glass ceiling in the 21st century: Understanding barriers to gender equality (pp. 99-124). Washington, DC, USA: American Psychological Association.

Bartlett, E. (2004). Rebellious feminism: Camus's ethic of rebellion and feminist thought. Cham, Switzerland: Springer.

Beede, D. N., Julian, T. A., Langdon, D., McKittrick, G., Khan, B., \& Doms, M. E. (2011). Women in STEM: A gender gap to innovation (Economics and Statistics Administration Issue Brief, 04-11). US Department of Commerce.

Bell, L. A., \& Adams, M. (2016). Theoretical foundations for social justice education. In M. Adams, L. A. Bell, \& P. Griffin (Eds.),

Teaching for diversity and social justice (pp. 21-44). Abingdon, United Kingdom: Routledge.

Belle, D., \& Doucet, J. (2003). Poverty, inequality, and discrimination as sources of depression among US women. Psychology of Women

Quarterly, 27(2), 101-113. https://doi.org/10.1111/1471-6402.00090

Bosworth, M. (2017). Engendering resistance: Agency and power in women's prisons. New York, NY, USA: Routledge.

Brehm, S. S., \& Brehm, J. W. (2013). Psychological reactance: A theory of freedom and control. New York, NY, USA: Academic Press.

Burn, S. M. (2005). Women across cultures: A global perspective. New York, NY, USA: McGraw-Hill.

Burn, S. M., Aboud, R., \& Moyles, C. (2000). The relationship between gender social identity and support for feminism. Sex Roles, 42(11-12), 1081-1089. https://doi.org/10.1023/A:1007044802798

Card, D., Cardoso, A. R., \& Kline, P. (2015). Bargaining, sorting, and the gender wage gap: Quantifying the impact of firms on the relative pay of women. The Quarterly fournal of Economics, 131(2), 633-686. https://doi.org/10.1093/qje/qjv038

Carter, R. T., \& Forsyth, J. (2010). Reactions to racial discrimination: Emotional stress and help-seeking behaviors. Psychological

Trauma: Theory, Research, Practice, and Policy, 2(3), Article 183. https://doi.org/10.1037/a0020102

Clark, D. (2019). Gender inequality in the United Kingdom-Statistics \& facts. Retrieved from

https://www.statista.com/topics/5273/gender-inequality-in-the-uk/ 
Clarke, H. D., Goodwin, M., \& Whiteley, P. (2017). Why Britain voted for Brexit: An individual-level analysis of the 2016 referendum vote. Parliamentary Affairs, 70(3), 439-464. https://doi.org/10.1093/pa/gsx005

Committee to Protect Journalists. (2016). Reports: 2016. Retrieved from https://cpj.org/reports/2016/

Corrigan, P. W., \& Watson, A. C. (2002). The paradox of self-stigma and mental illness. Clinical Psychology: Science and Practice, 9(1), 35-53. https://doi.org/10.1093/clipsy.9.1.35

Dardenne, B., Dumont, M., \& Bollier, T. (2007). Insidious dangers of benevolent sexism: Consequences for women's performance. Journal of Personality and Social Psychology, 93(5), Article 764. https://doi.org/10.1037/0022-3514.93.5.764

Dhir, A., Pallesen, S., Torsheim, T., \& Andreassen, C. S. (2016). Do age and gender differences exist in selfie-related behaviours? Computers in Human Behavior, 63, 549-555. https://doi.org/10.1016/j.chb.2016.05.053

Eaton, A. A., \& Visser, P. S. (2008). Attitude importance: Understanding the causes and consequences of passionately held views. Social and Personality Psychology Compass, 2(4), 1719-1736. https://doi.org/10.1111/j.1751-9004.2008.00125.x

Ellemers, N. (2018). Gender stereotypes. Annual Review of Psychology, 69, 275-298. https://doi.org/10.1146/annurev-psych-122216-011719

Fogarty, J. S. (1997). Reactance theory and patient noncompliance. Social Science \& Medicine, 45(8), 1277-1288. https://doi.org/10.1016/S0277-9536(97)00055-5

Ford, R., \& Goodwin, M. (2017). Britain after Brexit: A nation divided. Fournal of Democracy, 28(1), 17-30. https://doi.org/10.1353/jod.2017.0002

Freysinger, V. J., \& Flannery, D. (1992). Women's leisure: Affiliation, self-determination, empowerment and resistance? Loisir et société/ Society and Leisure, 15(1), 303-321. https://doi.org/10.1080/07053436.1992.10715419

Gilman, C. P. (2018). Women and economics. In D. B. Grusky \& J. Hill (Eds.), Inequality in the 21st century (pp. 31-33). New York, NY, USA: Routledge.

Grant, A. M., \& Gino, F. (2010). A little thanks goes a long way: Explaining why gratitude expressions motivate prosocial behavior. fournal of Personality and Social Psychology, 98(6), Article 946. https://doi.org/10.1037/a0017935

Hage, S. M. (2006). Profiles of women survivors: The development of agency in abusive relationships. fournal of Counseling \& Development, 84(1), 83-94. https://doi.org/10.1002/j.1556-6678.2006.tb00382.x

Hayes, A. F. (2017). Introduction to mediation, moderation, and conditional process analysis: A regression-based approach. New York, NY, USA: The Guilford Press.

Hayes, A. F., Glynn, C. J., \& Shanahan, J. (2005). Willingness to self-censor: A construct and measurement tool for public opinion research. International fournal of Public Opinion Research, 17, 299-323. https://doi.org/10.1093/ijpor/edh073

Henrich, J., Heine, S. J., \& Norenzayan, A. (2010). Most people are not WEIRD. Nature, 466(7302), Article 29. https://doi.org/10.1038/466029a

Hong, S.-M., \& Faedda, S. (1996). Refinement of the Hong psychological reactance scale. Educational and Psychological Measurement, 56, 173-182. https://doi.org/10.1177/0013164496056001014

Hooks, B. (2000). Feminism is for everybody: Passionate politics. London, United Kingdom: Pluto Press.

Hosterman, A. R., Johnson, N. R., Stouffer, R., \& Herring, S. (2018). Twitter, social support messages, and the \#MeToo Movement. The Journal of Social Media in Society, 7(2), 69-91.

Inglehart, R., Norris, P., \& Welzel, C. (2002). Gender equality and democracy. Comparative Sociology, 1(3), 321-345. https://doi.org/10.1163/156913302100418628

Itzchakov, G., DeMarree, K. G., Kluger, A. N., \& Turjeman-Levi, Y. (2018). The listener sets the tone: High-quality listening increases attitude clarity and behavior-intention consequences. Personality and Social Psychology Bulletin, 44(5), 762-778.

https://doi.org/10.1177/0146167217747874

Izard, C. E., Dougherty, F. E., Bloxom, B. M., \& Kotsch, W. E. (1974). The differential emotions scale: A method of measuring the subjective experience of discrete emotions (Unpublished manuscript). Vanderbilt University, Nashville, TN, USA.

Jack, D. C., \& Dill, D. (1992). The Silencing the Self Scale: Schemas of intimacy associated with depression in women. Psychology of Women Quarterly, 16(1), 97-106. https://doi.org/10.1111/j.1471-6402.1992.tb00242.x

Johansson, A., \& Vinthagen, S. (2016). Dimensions of everyday resistance: An analytical framework. Critical Sociology, 42(3), 417-435. https://doi.org/10.1177/0896920514524604 
Kachanoff, F. J., Cooligan, F., Caouette, J., \& Wohl, M. J. (2020). Free to fly the rainbow flag: The relation between collective autonomy and psychological well-being amongst LGBTQ+ individuals. Self and Identity. Advance online publication.

https://doi.org/10.1080/15298868.2020.1768890

Kachanoff, F. J., Taylor, D. M., Caouette, J., Khullar, T. H., \& Wohl, M. J. A. (2019). The chains on all my people are the chains on me: Restrictions to collective autonomy undermine the personal autonomy and psychological well-being of group members. fournal of Personality and Social Psychology, 116(1), 141-165. https://doi.org/10.1037/pspp0000177

Kalokerinos, E. K., Greenaway, K. H., \& Denson, T. F. (2015). Reappraisal but not suppression downregulates the experience of positive and negative emotion. Emotion, 15(3), Article 271. https://doi.org/10.1037/emo0000025

Kenny, D. A. (2017, February). MedPower: An interactive tool for the estimation of power in tests of mediation [Computer software]. Retrieved from https://davidakenny.shinyapps.io/MedPower/

Kim, H. S., \& Sherman, D. K. (2007). "Express yourself": Culture and the effect of self-expression on choice. Fournal of Personality and Social Psychology, 92(1), Article 1. https://doi.org/10.1037/0022-3514.92.1.1

Kim, H. S., Sherman, D. K., Ko, D., \& Taylor, S. E. (2006). Pursuit of comfort and pursuit of harmony: Culture, relationships, and social support seeking. Personality and Social Psychology Bulletin, 32(12), 1595-1607. https://doi.org/10.1177/0146167206291991

Kraus, M. W., Chen, S., \& Keltner, D. (2011). The power to be me: Power elevates self-concept consistency and authenticity. Fournal of Experimental Social Psychology, 47(5), 974-980. https://doi.org/10.1016/j.jesp.2011.03.017

Leach, C. W., \& Livingstone, A. G. (2015). Contesting the meaning of intergroup disadvantage: Towards a psychology of resistance. Journal of Social Issues, 71(3), 614-632. https://doi.org/10.1111/josi.12131

Legate, N., Weinstein, N., \& Przybylski, A. K. (2019). Parenting strategies and adolescents' cyberbullying behaviors: Evidence from a preregistered study of parent-child dyads. Fournal of Youth and Adolescence, 48(2), 399-409. https://doi.org/10.1007/s10964-018-0962-y

Lewis, R., Sharp, E., Remnant, J., \& Redpath, R. (2015). “Safe spaces”: Experiences of feminist women-only space. Sociological Research Online, 20(4), 105-118. https://doi.org/10.5153/sro.3781

Lorber, J. (1994). Paradoxes of gender. New York, NY, USA: Yale University Press.

Mack, P. (1995). Visionary Women: Ecstatic prophecy in seventeenth-century England. Berkeley, CA, USA: University of California Press.

Manago, A. M., Graham, M. B., Greenfield, P. M., \& Salimkhan, G. (2008). Self-presentation and gender on MySpace. fournal of Applied Developmental Psychology, 29(6), 446-458. https://doi.org/10.1016/j.appdev.2008.07.001

McMahill, C. (2001). Self-expression, gender, and community: A Japanese feminist English class. In A. Pavlenko, A. Blackledge, I. Piller, \& M. Teutsch-Dwyer (Eds.), Multilingualism, second language learning, and gender (pp. 307-344). Berlin, Germany: Walter de Gruyter.

Miller, K. A. (1997). Dress: Private and secret self-expression. Clothing and Textiles Research fournal, 15(4), 223-234. https://doi.org/10.1177/0887302X9701500404

Moore, S., \& Fitzsimons, G. (2007). What's yours is mine: Self-construal and reactance on behalf of others. ACR North American Advances, 34, 223-225.

Moss, N. E. (2002). Gender equity and socioeconomic inequality: A framework for the patterning of women's health. Social Science \& Medicine, 54(5), 649-661. https://doi.org/10.1016/S0277-9536(01)00115-0

Nussbaum, M. C., \& Glover, J. (Eds.). (1995). Women, culture, and development: A study of human capabilities. Oxford, United Kingdom: Clarendon Press.

Pennebaker, J. W., \& Chung, C. K. (2011). Expressive writing: Connections to physical and mental health. In H. S. Friedman (Ed.), Oxford handbook of health psychology (pp. 417-437). https://doi.org/10.1093/oxfordhb/9780195342819.013.0018

Phillips, N. L., Adams, G., \& Salter, P. S. (2015). Beyond adaptation: Decolonizing approaches to coping with oppression. fournal of Social and Political Psychology, 3(1), 365-387. https://doi.org/10.5964/jspp.v3i1.310

Richards, J. M., \& Gross, J. J. (2000). Emotion regulation and memory: The cognitive costs of keeping one's cool. fournal of Personality and Social Psychology, 79(3), 410-424. https://doi.org/10.1037/0022-3514.79.3.410

Rosales, C., \& Langhout, R. D. (2020). Just because we don't see it, doesn't mean it's not there: Everyday resistance in psychology. Social and Personality Psychology Compass, 14(1), Article e12508. https://doi.org/10.1111/spc3.12508

Ryan, R. M., \& Deci, E. L. (2017). Self-determination theory: Basic psychological needs in motivation, development, and wellness. New York, NY, USA: The Guilford Press. 
Sakr, N. (Ed.). (2004). Women and media in the Middle East: Power through self-expression (Vol. 41). London, United Kingdom: I.B. Tauris.

Schmitt, M. T., Branscombe, N. R., \& Postmes, T. (2003). Women's emotional responses to the pervasiveness of gender discrimination. European fournal of Social Psychology, 33(3), 297-312. https://doi.org/10.1002/ejsp.147

Scott, J. C. (1989). Everyday forms of resistance. The Copenhagen fournal of Asian Studies, 4, 33-33. https://doi.org/10.22439/cjas.v4i1.1765

Shaw, S. M. (2001). Conceptualizing resistance: Women's leisure as political practice. fournal of Leisure Research, 33(2), $186-201$. https://doi.org/10.1080/00222216.2001.11949937

Shepherd, M., Erchull, M. J., Rosner, A., Taubenberger, L., Queen, E. F., \& McKee, J. (2011). "I'll get that for you": The relationship between benevolent sexism and body self-perceptions. Sex Roles, 64(1-2), 1-8. https://doi.org/10.1007/s11199-010-9859-2

Soueif, A. (2011). Tweets from Tahrir: Egypt's revolution as it unfolded, in the words of the people who made it. New York, NY, USA: OR Books.

Stanton, A. L., Danoff-Burg, S., Sworowski, L. A., Collins, C. A., Branstetter, A. D., Rodriguez-Hanley, A., . . Austenfeld, J. L. (2002). Randomized, controlled trial of written emotional expression and benefit finding in breast cancer patients. fournal of Clinical Oncology, 20(20), 4160-4168. https://doi.org/10.1200/JCO.2002.08.521

Swim, J. K., Eyssell, K. M., Murdoch, E. Q., \& Ferguson, M. J. (2010). Self-silencing to sexism. fournal of Social Issues, 66(3), $493-507$. https://doi.org/10.1111/j.1540-4560.2010.01658.x

Tajfel, H., \& Turner, J. C. (1979). An integrative theory of intergroup conflict. In M. J. Hatch \& M. Schultz (Eds.), Organizational identity: A reader (pp. 56-65). Oxford, United Kingdom: Oxford University Press.

Thompson, J. M. (1995). Silencing the self: Depressive symptomatology and close relationships. Psychology of Women Quarterly, 19(3), 337-353. https://doi.org/10.1111/j.1471-6402.1995.tb00079.x

UN Women. (2013). Ad series reveals widespread sexism. Retrieved from http://www.unwomen.org/en/news/stories/2013/10/women-should-ads

UN Women. (2015). Human right of women. Retrieved from https:/www.unwomen.org/en/digital-library/multimedia/2015/12/infographic-human-rights-women

Van Petegem, S., Soenens, B., Vansteenkiste, M., \& Beyers, W. (2015). Rebels with a cause? Adolescent defiance from the perspective of reactance theory and self-determination theory. Child Development, 86(3), 903-918. https://doi.org/10.1111/cdev.12355

Vasilopoulou, S., \& Talving, L. (2019). British public opinion on Brexit: Controversies and contradictions. European Political Science, 18(1), 134-142. https://doi.org/10.1057/s41304-018-0156-9

Woodford, M. R., Han, Y., Craig, S., Lim, C., \& Matney, M. M. (2014). Discrimination and mental health among sexual minority college students: The type and form of discrimination does matter. fournal of Gay \& Lesbian Mental Health, 18(2), 142-163. https://doi.org/10.1080/19359705.2013.833882

Wortman, C. B., \& Brehm, J. W. (1975). Responses to uncontrollable outcomes: An integration of reactance theory and the learned helplessness model. In Advances in experimental social psychology (Vol. 8, pp. 277-336). New York, NY, USA: Academic Press.

Zillig, L. M. P., Hemenover, S. H., \& Dienstbier, R. A. (2002). What do we assess when we assess a Big 5 trait? A content analysis of the affective, behavioral, and cognitive processes represented in Big 5 personality inventories. Personality and Social Psychology Bulletin, 28(6), 847-858. https://doi.org/10.1177/0146167202289013 